\title{
The discovery of the BABA receptor: scientific implications and application potential
}

\author{
Roland E. Schwarzenbacher, Estrella Luna * and Jurriaan Ton * \\ Animal and Plant Sciences Department, The University of Sheffield, Sheffield, UK \\ *Correspondence: e.luna-diez@sheffield.ac.uk; j.ton@sheffield.ac.uk
}

Edited by:

Andrés A. Borges, Consejo Superior de Investigaciones Científicas, Spain

Reviewed by:

Albor Dobon Alonso, Postdoctoral Researcher, UK

Keywords: ß-aminobutyric acid (BABA), plant defense priming, plant-pathogen interactions, aspartyl-tRNA synthetase, plant immunity

\section{A commentary on}

Plant perception of $\beta$-aminobutyric acid is mediated by an aspartyl-tRNA synthetase

by Luna, E., van Hulten, M., Zhang, Y., Berkowitz, O., López, A., Pétriacq, P., et al. (2014). Nat. Chem. Biol. 10, 450-456. doi: 10.1038/nchembio. 1520

A significant proportion of global crop production is annually lost to pests and diseases (Savary et al., 2012). While pesticides help to reduce these losses, there is growing concern about pesticide resistance and their impacts on health and environment. Integrated Pest Management (IPM) aims to reduce pesticide usage through a combination of different strategies, including resistant crop cultivars, monitoring disease status, and mechanical and biological control (Birch et al., 2011; Chandler et al., 2011). A potentially novel IPM tool is plant priming agents: stimuli that sensitize the plant's immune system for augmented activation against future pathogen/herbivore attacks. Because priming leads to augmented activation of multi-genic defense mechanisms (Ton et al., 2006; Ahmad et al., 2010), the resulting resistance has the potential to be more durable than protection by single resistance (R-) genes. Despite this advantage, priming agents are not widely used in agriculture, partly because they often do not provide the same level of protection as conventional pesticides and Rgenes (Walters et al., 2013). However, the advancement of IPM has spurred increased interest in exploiting priming agents in sustainable crop protection schemes.

Arguably the most effective priming agent is $\beta$-aminobutyric acid (BABA). This non-protein amino acid primes defense reactions that are controlled by salicylic acid (SA)-dependent and -independent signaling pathways (Zimmerli et al., 2000; Ton et al., 2005), conferring protection in different plant species against an exceptionally broad spectrum of stresses, including microbial pathogens, herbivores, and abiotic stresses (Jakab et al., 2001; Cohen, 2002). Unfortunately, BABA also has an undesirable side effect: it reduces plant growth (Wu et al., 2010). While this growth penalty is outweighed by its protective effects in environments with high disease pressure, it can be quite severe at higher doses under disease-free conditions (Van Hulten et al., 2006).

Until now, understanding of the molecular mechanisms underpinning the tradeoff between BABA-IR and BABA-induced growth repression was limited by insufficient knowledge of how this chemical is perceived in plants. A recent study, however, has provided new insight in this matter (Luna et al., 2014). A screen for Arabidopsis mutants in BABA-IR against the biotrophic oomycete Hyaloperonospora arabidopsidis led to the identification of the Impaired in BABA-induced Immunity 1 (IBI1) gene, encoding an aspartyl-tRNA synthetase (AspRS). Unlike previously identified genes controlling either SAdependent, or SA-independent BABA-IR (Ton et al., 2005), the ibi1-1 mutation was found to block both priming responses to BABA, indicating unilateral control of BABA-induced resistance by IBI1.
The stereochemical similarity between the amino acid substrate of IBI1 (Laspartate; L-asp) and the active enantiomer of BABA (R-BABA) suggested that IBI1 might function as the BABA receptor. This hypothesis was supported by several indirect lines of evidence; apart from loss of BABA-IR by independent mutations in IBI1, computational models of BABA-binding to AspRS enzymes indicated high-affinity binding of R-BABA in a similar molecular orientation as L-asp, while treatment with active R-BABA caused cellular L-asp accumulation. Further evidence for receptor functionality by IBI1 came from the in planta demonstration that R-BABA physically binds to IBI1. It was concluded that R-BABA binds the L-aspbinding domain of IBI1, thereby disrupting canonical AspRS activity and priming the protein for non-canonical defense activity. This model also predicts that RBABA increases uncharged tRNA ${ }^{\text {asp }}$ accumulation. Across eukaryotes, uncharged tRNA serves as a conserved signal for metabolic imbalance by activating the protein kinase GCN2 (Dong et al., 2000; Dever and Hinnebusch, 2005), which in turn inhibits translational activity via phosphorylation of eukaryotic translation initiation factor eIF $2 \alpha$ (Wek et al., 2006; Li et al., 2013). Evidence that this stress pathway is activated by BABA came from the demonstration that stressinducing concentrations of BABA activate GCN2-dependent eIF2 $\alpha$ phosphorylation. Moreover, the gcn2-1 mutant of Arabidopsis was strongly reduced in BABA-induced growth inhibition, while it remained unaffected in BABA-induced 
resistance. This latter finding not only confirmed the critical role of GCN2 in BABA-induced stress, it also demonstrated that BABA-IR and BABA-induced stress are controlled by separate pathways.

An important question from the work by Luna et al. (2014) is why plants have evolved a specific receptor protein to a xenobiotic chemical? Does BABA mimic a natural ligand, or does it induce a physiological state that is indicative of pathogen attack? An important clue came from the finding that $I B I 1$ transcription is increased following pathogen attack, while transgenic overexpression of IBI1 enhances basal disease resistance through priming of inducible defenses. Hence, IBI1 can contribute to basal resistance in the absence of BABA. One of the emerging scenarios is that IBI1 contributes to basal resistance as a sensor of cellular Laspartate (Figure 1). A sudden decline in cellular aspartate concentrations could indicate parasitization by a biotrophic pathogen and would reduce canonical AspRS activity by IBI1. It was suggested that this deprivation of canonical AspRS activity primes the alternative defense function of IBI1. This situation is mimicked by R-BABA, which blocks L-asp-IBI1 binding, tricking the protein into sensing low L-aspartate levels (Figure 1). However, it still takes a secondary stress signal after pathogen attack to fully activate the defense modus of IBI1, resulting in enhanced IBII

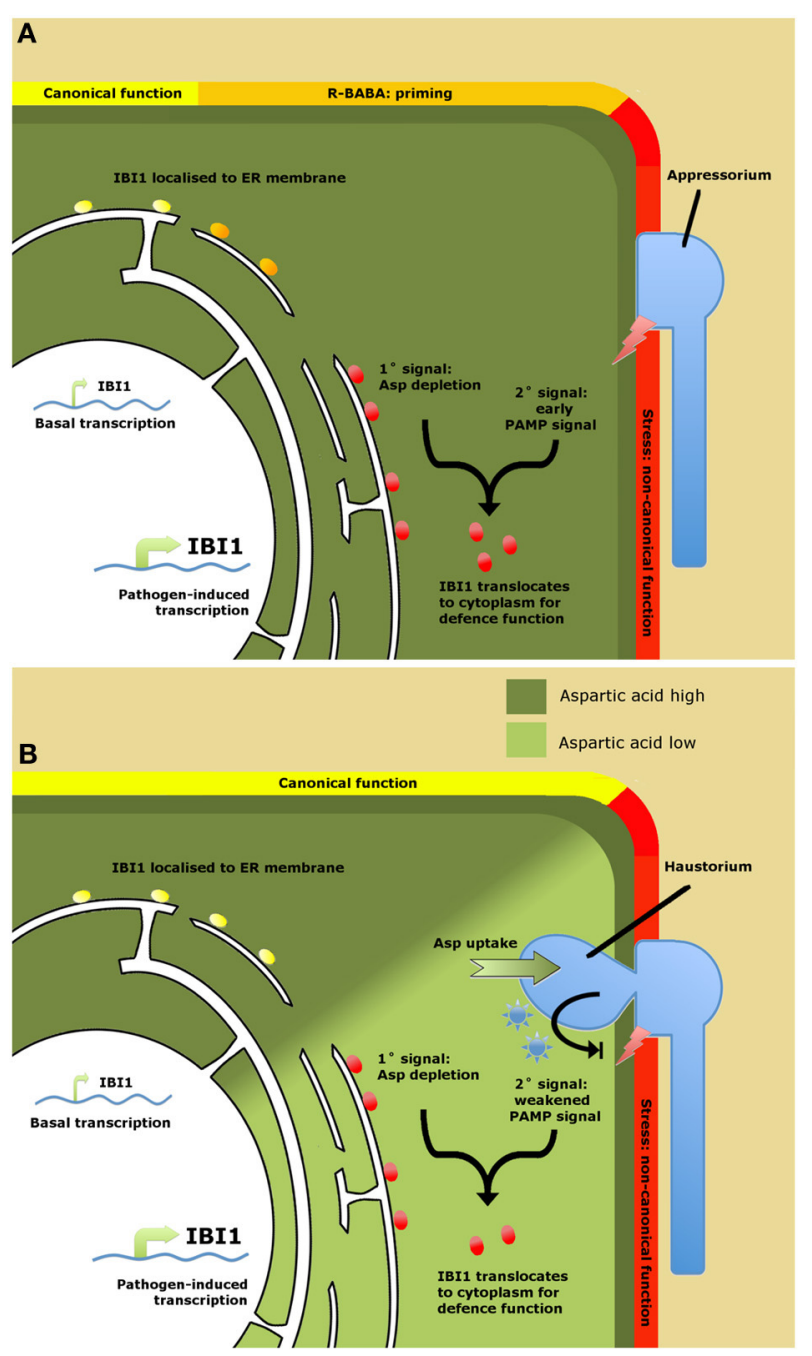

FIGURE 1 | Model of IBI1 as a regulator of BABA-induced resistance (A) and as a "depleted-self sensor" in basal resistance (B). (A) Role of $I B \mid 1$ in BABA-induced resistance (BABA-IR). Binding of R-BABA to ER-localized IBI1 protein (yellow circles) deprives the protein of canonical aspartyl-tRNA synthetase (AspRS) activity, which "primes" the protein's non-canonical defense activity against pathogen attack (orange circles). Detection of pathogen-associated molecular patterns (PAMPs) during the early stages of pathogen infection boosts $/ B / 1$ gene transcription and triggers translocation of IBI1 to the cytosol, where it activates defense activity through interaction with immune-regulatory proteins (red circles). (B) Role of IBI1 in basal resistance. Successful pathogen infection leads to suppression of PAMP recognition through the action of pathogen-derived effectors (blue asterisks). Ongoing parasitization and amino acid uptake by the pathogen lowers cellular L-asp levels, depriving IBI1 from its canonical AspRS activity. This, together with effector-weakened PAMP perception, boosts IBI1 transcription and elicits translocation of the protein from the ER to the cytosol, where it activates broad-spectrum defenses (red circles). Hence, IBI1 acts as a "depleted-self" sensor to counteract effector-triggered suppression of "nonself recognition." 
transcription, subcellular translocation of IBI1 from the ER to the cytoplasm, and augmented defense induction. Since $\mathrm{BABA}$ has been reported to prime PAMPtriggered immunity (PTI; Singh et al., 2012), the logical conclusion is that this secondary signal are PAMPs. Hence, IBI1 primes PTI by means of "depleted-self recognition." This mechanism provides plants with an improved capability to recognize biotrophic pathogens, thereby counteracting their specialist ability to suppress "nonself recognition" of PAMPs (Dodds and Rathjen, 2010).

Luna et al. (2014) also revealed a caveat concerning agricultural exploitation of BABA: because the chemical blocks the conserved aspartate-binding domain of AspRS enzymes, it might also impact human AspRS activity. However, future research might provide opportunities to engineer constitutively primed crop varieties without relying on BABA application. It was already shown that transgenic over-expression of IBI1 boosts basal resistance without causing phytotoxicity. This level of BABA-independent disease protection might be improved further by engineering constitutively primed IBI1 protein that is of similar configuration as BABA-bound wild-type IBI1. Such approach would not block native AspRS activity and therefore not activate the GCN2-dependent stress pathway. In summary, the study has unveiled a novel concept in plant immune regulation and given new direction toward the exploitation of defense priming in crop protection.

\section{ACKNOWLEDGMENTS}

Research in Jurriaan Ton's laboratory is supported by a consolidator grant from the European Research Council (ERC; no. 309944-PrimeA-Plant) to Jurriaan Ton and a Research Leadership Award from the Leverhulme Trust (no. RL-2012-042) to Jurriaan Ton.

\section{REFERENCES}

Ahmad, S., Gordon-Weeks, R., Pickett, J., and Ton, J. (2010). Natural variation in priming of basal resistance: from evolutionary origin to agricultural exploitation. Mol. Plant Pathol. 6, 817-827. doi: 10.1111/j.1364-3703.2010. 00645.x

Birch, A. N. E., Begg, G. S., and Squire, G. R. (2011). How agro-ecological research helps to address food security issues under new IPM and pesticide reduction policies for global crop production systems. J. Exp. Bot. 62, 3251-3261. doi: 10.1093/jxb/ err064

Chandler, D., Bailey, A. S., Tatchell, G. M., Davidson, G., Greaves, J., and Grant, W. P. (2011). The development, regulation and use of biopesticides for integrated pest management. Philos. Trans. R. Soc. B Biol. Sci. 366, 1987-1998. doi: 10.1098/rstb.2010.0390

Cohen, Y. (2002). $\beta$-aminobutyric acid-induced resistance against plant pathogens. Plant Dis. 86, 448-457. doi: 10.1094/PDIS.2002. 86.5.448

Dever, T. E., and Hinnebusch, A. G. (2005). GCN2 whets the appetite for amino acids. Mol. Cell 18, 141-142. doi: 10.1016/j.molcel.2005.03.023

Dodds, P. N., and Rathjen, J. P. (2010). Plant immunity: towards an integrated view of plant-pathogen interactions. Nat. Rev. Genet. 11, 539-548. doi: $10.1038 / \operatorname{nrg} 2812$

Dong, J. S., Qiu, H. F., Garcia-Barrio, M., Anderson, J., and Hinnebusch, A. G. (2000). Uncharged tRNA activates GCN2 by displacing the protein kinase moiety from a bipartite tRNA-Binding domain. Mol. Cell 6, 269-279. doi: 10.1016/S10972765(00)00028-9

Jakab, G., Cottier, V., Toquin, V., Rigoli, G., Zimmerli, L., Métraux, J.-P., et al. (2001). $\beta$-aminobutyric acid-induced resistance in plants. Eur. J. Plant Pathol. 107, 29-37. doi: 10.1023/A:1008730 721037

Li, M. W., Auyeung, W. K., and Lam, H. M. (2013). The GCN2 homologue in Arabidopsis thaliana interacts with uncharged tRNA and uses Arabidopsis eIF2alpha molecules as direct substrates. Plant Biol. (Stuttg). 15, 13-18. doi: 10.1111/j.1438-8677.2012. 00606.x

Luna, E., Van Hulten, M., Zhang, Y., Berkowitz, O., López, A., Pétriacq, P., et al. (2014). Plant perception of $\beta$-aminobutyric acid is mediated by an aspartyl-tRNA synthetase. Nat. Chem. Biol. 10, 450-456. doi: 10.1038/ nchembio. 1520

Savary, S., Ficke, A., Aubertot, J.-N., and Hollier, C. (2012). Crop losses due to diseases and their implications for global food production losses and food security. Food Secur. 4, 519-537. doi: 10.1007/s12571-012-0200-5

Singh, P., Kuo, Y.-C., Mishra, S., Tsai, C.-H., Chien, C.-C., Chen, C.-W., et al. (2012). The lectin receptor kinase-VI.2 is required for priming and positively regulates arabidopsis patterntriggered immunity. Plant Cell 24, 1256-1270. doi: 10.1105/tpc.112.095778

Ton, J., Jakab, G., Toquin, V., Flors, V., Iavicoli, A., Maeder, M. N., et al. (2005). Dissecting the beta-aminobutyric acid-induced priming phenomenon in Arabidopsis. Plant Cell 17, 987-999. doi: $10.1105 /$ tpc. 104.029728

Ton, J., Pieterse, C. J., and Loon, L. C. (2006). “The relationship between basal and induced resistance in Arabidopsis," in Multigenic and Induced Systemic Resistance in Plants, eds S. Tuzun and E. Bent (New York, NY: Springer), 197-224.

Van Hulten, M., Pelser, M., Van Loon, L., Pieterse, C. M. J., and Ton, J. (2006). Costs and benefits of priming for defense in Arabidopsis. Proc. Natl. Acad. Sci. U.S.A. 103, 5602-5607. doi: 10.1073/pnas.0510213103

Walters, D. R., Ratsep, J., and Havis, N. D. (2013). Controlling crop diseases using induced resistance: challenges for the future. J. Exp. Bot. 64, 1263-1280. doi: 10.1093/jxb/ert026

Wek, R. C., Jiang, H. Y., and Anthony, T. G. (2006). Coping with stress: eIF2 kinases and translational control. Biochem. Soc. Trans. 34, 7-11. doi: 10.1042/BST0340007

Wu, C.-C., Singh, P., Chen, M.-C., and Zimmerli, L. (2010). L-Glutamine inhibits beta-aminobutyric acid-induced stress resistance and priming in Arabidopsis. J. Exp. Bot. 61, 995-1002. doi: 10.1093/jxb/erp363

Zimmerli, L., Jakab, G., Métraux, J.-P., and MauchMani, B. (2000). Potentiation of pathogen-specific defense mechanisms in Arabidopsis by baminobutyric acid. Proc. Natl. Acad. Sci. U.S.A. 97, 12920-12925. doi: 10.1073/pnas.230416897

Conflict of Interest Statement: The authors declare that the research was conducted in the absence of any commercial or financial relationships that could be construed as a potential conflict of interest.

Received: 24 May 2014; paper pending published: 09 June 2014; accepted: 09 June 2014; published online: 25 June 2014.

Citation: Schwarzenbacher RE, Luna E and Ton J (2014) The discovery of the BABA receptor: scientific implications and application potential. Front. Plant Sci. 5:304. doi: $10.3389 / f p l s .2014 .00304$

This article was submitted to Plant Physiology, a section of the journal Frontiers in Plant Science.

Copyright (C) 2014 Schwarzenbacher, Luna and Ton. This is an open-access article distributed under the terms of the Creative Commons Attribution License (CC BY). The use, distribution or reproduction in other forums is permitted, provided the original author(s) or licensor are credited and that the original publication in this journal is cited, in accordance with accepted academic practice. No use, distribution or reproduction is permitted which does not comply with these terms. 